\title{
EDITORIALS
}

\section{Obstructive sleep apnoea: quantifying its association with obesity and snoring}

\section{See linked article by Wall et al. on pg 371}

\section{*Ravi Parekh1, Edward Green', Azeem Majeed² \\ 1 Honorary Clinical Research Fellow, Department of Primary Care and Public Health, Imperial College London, London, UK \\ 2 Professor of Primary Care, Department of Primary Care and Public Health, Imperial College London, London, UK}

*Correspondence: Dr Ravi Parekh, Department of Primary Care and Public Health, Imperial College London, Reynolds Building, Cross Hospital Campus, St Dunstan's Road, London W6 8RP, UK Tel: +44 (0)20 7594 3368/3362 Fax: +44 (0)20 75940854 Email: r.parekh@imperial.ac.uk

Obstructive sleep apnoea (OSA) is a chronic condition with an estimated prevalence of between $2-3 \%$ in the UK, although a large proportion of individuals with OSA remain undiagnosed. ${ }^{1,2}$ It is caused by repetitive pharyngeal collapse during sleep, which is restored with recurrent arousals and activation of the sympathetic nervous system. Interest around the condition has increased following evidence showing an association of OSA with hypertension, type 2 diabetes mellitus and coronary artery disease, together with adverse health outcomes. ${ }^{3-5}$

The burden of obesity remains one of the largest public health issues facing the UK. Studies suggest that $67 \%$ of men and $69 \%$ of women in England are obese or overweight. ${ }^{6}$ Such levels of obesity lead to wide ranging public health consequences, including significant medical, social, and financial burdens on individuals and society. Estimates suggest that the annual direct cost of obesity to the UK National Health Service (NHS) stands at $£ 3.2$ billion. ${ }^{6}$ The relationship between OSA and obesity remains complex and multi-factorial; a recent review by Carter \& Watenpaugh demonstrates the bidirectional causality between OSA and obesity, which can lead to a cycle of worsening symptoms of both conditions. ${ }^{7}$ This relationship is well documented in the literature. ${ }^{8}$ However, there has been no previous study to quantify this association within the general population in the UK.

The study by Wall and colleagues ${ }^{9}$ in this issue of the $P C R J$ is the first time the strength of association between OSA, snoring and obesity has been investigated in the UK using a large primary care database. In a cross-sectional study of records from The Health Improvement Network (THIN) database, and controlling for confounding factors such as gender, age, region, and socioeconomic status, they used logistic regression techniques to explore the relationship between body mass index (BMI), a history of snoring, and a diagnosis of OSA in the over-50s in the UK. They report that $88 \%$ of patients aged 50 and over had a recorded $\mathrm{BMI}$, and that $55 \%$ of patients with a recorded BMl were overweight or obese, with the prevalence of OSA increasing progressively with increasing BMI. 96\% of patients with a diagnosis of OSA had a recorded BMI. Perhaps the most important result from the study is that individuals with a BMI over $40 \mathrm{~kg} / \mathrm{m}^{2}$ were 27 times more likely to have a diagnosis of OSA when compared to those with a normal BMI. $27 \%$ of people with a diagnosis of OSA are recorded as being snorers, an equivalent multivariate analysis odds ratio for OSA in snorers of 26. Interestingly, the levels of OSA decreased with increasing age and deprivation after controlling for confounding factors.

When comparing these results to those from other studies, the initial striking factor is the low prevalence of a diagnosis of OSA $(0.6 \%)$ in those with a recorded BMI. ${ }^{9}$ The reasons for this may include coding variability on primary care computer systems, under-diagnosis by clinicians, or people with OSA not presenting to primary healthcare services. The possibility of selection bias is also discussed, with regard to general practitioners (GPs) being more likely to suspect and diagnose OSA in a patient with a high BMl. This could lead to patients with OSA and a normal BMI being under-represented within this study. The inverse relationship of deprivation and age with OSA is a new finding, which requires further investigation.

This research highlights some important points for primary healthcare policy and practice. The prevalence of OSA seen here ${ }^{9}$ is lower than previous estimates in the literature, based on studies of high-risk populations. The figure in this paper may, however, represent a more accurate reflection of the current situation in the UK. One possible reason suggested for the low OSA prevalence is that a range of computer Read-codes may be utilised for the same condition. Therefore, it is essential that clinicians accurately code diagnoses in their practice to enable a true prevalence to be calculated for allocation of resources. Clinicians should also be encouraged to ask about OSA, particularly when managing people with significant obesity.

The strong degree of association of OSA with obesity and snoring indicates that these factors should be central in flagging GPs towards the condition and referring to secondary care for diagnostic studies. However, there is also a significant proportion (40\%) of total OSA diagnoses in people with BMls under $30 \mathrm{~kg} / \mathrm{m}^{2}$, and so GPs should be open-minded about this diagnosis in symptomatic individuals who are not obese.

The finding that people from lower socio-economic backgrounds 
are less likely to be diagnosed with OSA, despite having higher average BMls, suggests that a lack of symptom awareness in these populations may be leading to delayed presentation or nonpresentation to primary care, or even a systematic under-diagnosis of OSA in these groups by GPs. Alternatively it could be that there is a true reduction in prevalence of OSA with increasing levels of deprivation, but this seems unlikely given evidence on this association from research groups in other countries, and the well-known associations between deprivation and adverse health outcomes. ${ }^{10-12}$ This may indicate a need for health campaigns to publicise the condition, its symptoms and treatment options, targeted at people from the more deprived sectors of society.

The authors report that the evident reduction in OSA prevalence with increasing age could be secondary to discrimination or a focus on other co-morbidities in the elderly. ${ }^{9}$ This is a possibility, and given the impact on quality of life and the potential effects of conditions associated with OSA, investigation and diagnosis should not be delayed or ignored in primary care. Another explanation is that these OSA-associated diseases - and the mortality linked with them - may be causing the fall in OSA prevalence as age increases, as observed in this study.

This study by Wall and colleagues ${ }^{9}$ gives pointers to future research on OSA, as well as illustrating the research potential of large databases derived from electronic primary care records. ${ }^{13}$ Given the restricted age-range included in this study's target population, the strongly predictive factor of $\mathrm{BMI}$, and the rapidly rising obesity rates amongst younger age-groups in the UK, additional studies should be carried out to evaluate the contribution of obesity to OSA in people aged under 50. This may be especially significant for childhood OSA sufferers, considering the current childhood obesity epidemic in the UK and elsewhere. Further research is also required to investigate the apparent counter-intuitive findings in this paper regarding the association of OSA with socio-economic status and age.

Acknowledgements The Department of Primary Care \& Public Health at Imperial College London is grateful for support from the NW London NIHR Collaboration for Leadership in Applied Health Research \& Care (CLAHRC), the Imperial NIHR Biomedical Research Centre, and the Imperial Centre for Patient Safety and Service Quality (CPSSQ).

Conflicts of interest The authors declare that they have no conflicts of interest in relation to this article.
Contributorship Ravi Parekh and Edward Green wrote the manuscript. Professor Azeem Majeed provided feedback, guidance, critical review and revision of the manuscript.

Commissioned article; not externally peer-reviewed; accepted 11th September 2012 online 22nd October 2012

(C) 2012 Primary Care Respiratory Society UK. All rights reserved

http://dx.doi.org/10.4104/pcrj.2012.00091

Prim Care Respir J 2012; 21(4): 361-362

\section{References}

1. Punjabi N. The Epidemiology of Adult Obstructive Sleep Apnea. Proc Am Thorac Soc 2008:5:136-43. http://dx.doi.org/10.1513/pats.200709-155MG

2. Davies RJO, Stradling JR. The epidemiology of sleep apnoea. Thorax 1996;51(Supp 2):S65-S70. http://dx.doi.org/10.1136\%2Fthx.51.Suppl_2.S65

3. Peppard PE, Young T, Palta M, Skatrud J. Prospective study of the association between sleep-disordered breathing and hypertension. N Engl J Med 2000; 342(19):1378-84. http://dx.doi.org/10.1056\%2FNEJM200005113421901

4. Peker $Y$, Carlson J, Hedner J. Increased incidence of coronary artery disease in sleep apnoea: a long-term follow-up. Eur Respir J 2006;28:596-602. http://dx.doi.org/10.1183\%2F09031936.06.00107805

5. Punjabi NM, Polotsky VY. Disorders of glucose metabolism in sleep apnea. J Appl Physiol 2005;99(5):1998-2007.

http://dx.doi.org/10.1152\%2Fjapplphysiol. 00695.2005

6. Allender S, Rayner M. The burden of overweight and obesity-related ill health in the UK. Obesity reviews 2007;8:467-73. http://dx.doi.org/10.1111\%2Fj.1467-789X.2007.00394.x

7. Carter R, Watenpaugh DE. Obesity and obstructive sleep apnea: Or is it OSA and obesity? Pathophysiology 2008;15:71-7.

http://dx.doi.org/10.1016\%2Fj. pathophys.2008.04.009

8. Daltro C, Gregorio PB, Alves E et al. Prevalence and Severity of Sleep Apnea in a Group of Morbidly Obese Patients. Obesity Surgery 2007;17:809-14 http://dx.doi.org/10.1007\%2Fs11695-007-9147-6

9. Wall H, Smith C, Hubbard R. BMI and obstructive sleep apnoea in the UK: a crosssectional study of the over-50s. Prim Care Respir J 2012;21(4):371-6.

10. Grandner MA, Patel NP, Gehrman PR et al. Who gets the best sleep? Ethnic and socioeconomic factors related to sleep complaints. Sleep Med 2010;11(5):470-8. http://dx.doi.org/10.1016\%2Fj.sleep.2009.10.006

11. Li X, Sundquist $K$, Sundquist J. Socioeconomic status and occupation as risk factors for obstructive sleep apnea in Sweden: a population-based study. Sleep Med 2008;9(2):129-36. http://dx.doi.org/10.1016\%2Fj.sleep.2007.02.003

12. Reddy EV, Kadhiravan T, Mishra HK et al. Prevalence and risk factors of obstructive sleep apnea among middle-aged urban Indians: a community-based study. Sleep Med 2009;10(8):913-18. http://dx.doi.org/10.1016\%2Fj.sleep.2008.08.011

13. Majeed A. Sources, uses, strengths and limitations of data collected in primary care in England. Health Stat Q 2004:21:5-14.

\section{Body mass index and obstructive sleep apnoea}

See linked article by Wall et al. on pg 371

\section{*John Shneerson'}

1 Consultant Physician and Director, Respiratory Support and Sleep Centre, Papworth Hospital, Cambridge, UK

*Correspondence: Dr John Shneerson, Director RSSC, Papworth Hospital NHS Foundation Trust, Papworth Everard, Cambs, CB23 3RE, UK

Tel: +44 (0)1480 830541 Fax: +44 (0)1480 830620

E-mail: c/o Jane.warmer@papworth.nhs.uk
The article by Wall et al. in this issue of the $P C R J^{1}$ is one of the largest epidemiological studies ever to be carried out to assess the link between obstructive sleep apnoea (OSA) and obesity. Data were analysed from over a million subjects aged 50 years or over, and the body mass index (BMI) had been calculated in as many as $88 \%$. The aim of the study was to assess the prevalence of OSA and snoring, and to evaluate any correlation with BMI, age, gender and social class.

The study suffers from the disadvantage that the diagnosis of OSA was based purely on whether or not this was recorded as a Read computer code in the primary care notes. This clearly leaves scope for 